\title{
M-Polynomials and Degree-Based Topological Indices of the Crystallographic Structure of Molecules
}

\author{
Wei Gao ${ }^{1}$, Muhammad Younas ${ }^{2}$, Adeel Farooq ${ }^{2}$, Abid Mahboob ${ }^{3}$ and Waqas Nazeer ${ }^{4, *}$ (i) \\ 1 School of Information Science and Technology, Yunnan Normal University, Kunming 650500, China; \\ gaowei@ynnu.edu.cn \\ 2 Department of Mathematics, COMSATS University Islamabad, Lahore Campus, Lahore 54000, Pakistan; \\ muhammadyounas@cuilahore.edu.pk (M.Y.); adeelfarooq@cuilahore.edu.pk (A.F.) \\ 3 Department of Mathematics, University of Education, Vehari Campus, Lahore 54000, Pakistan; \\ abid.mahboob@ue.edu.pk \\ 4 Division of Science and Technology, University of Education, Lahore 54000, Pakistan \\ * Correspondence: nazeer.waqas@ue.edu.pk
}

Received: 4 September 2018; Accepted: 28 September 2018; Published: 3 October 2018

\begin{abstract}
Topological indices are numerical parameters used to study the physical and chemical properties of compounds. In quantitative structure-activity relationship QSARs, topological indices correlate the biological activity of compounds with their physical properties like boiling point, stability, melting point, distortion, and strain energy etc. In this paper, we determined the M-polynomials of the crystallographic structure of the molecules $\mathrm{Cu}_{2} \mathrm{O}$ and $\mathrm{T}_{\mathrm{i}} \mathrm{F}_{2}[p, q, r]$. Then we derived closed formulas for some well-known topological indices using calculus. In the end, we used Maple 15 to plot surfaces associated with the topological indices of $\mathrm{Cu}_{2} \mathrm{O}$ and $\mathrm{T}_{\mathrm{i}} \mathrm{F}_{2}[p, q, r]$.
\end{abstract}

Keywords: M-polynomial; zagreb index; randić index; crystallographic structure

\section{Introduction}

In the medication mathematical model, the structure of medication is taken as an undirected graph, where vertices and edges are taken as atoms and chemical bonds. With the rapid advancement of medicine manufacture, a huge number of new medications are created every year. Henceforth, it requires a colossal amount of work to decide on the pharmacological, compound and biological characteristics of these new medications, and such workloads turn out to be increasingly particular and bunched together. It requires sufficient reagents equipment and partners to test the performances and the reactions of new medications. Be that as it may, in run down poor nations and regions, (for example, certain urban communities and nations in South America, Southeast Asia, Africa and India), there is no adequate cash to acquire reagents and equipment which can be utilized to measure the biochemical properties.

Luckily, numerous past studies [1,2] have pointed out that chemical and pharma codynamic attributes of medications and their atomic structures are firmly connected. In the event that we compute indicators of these graphs of drug molecules [3-6] with the perspective of characterizing the topological index, pharmaceutical researchers could well think that it is helpful to understand the medicinal properties, which can make up for the deformities of drug and chemical experiments. From this outlook, the strategies on topological index calculation are exceptionally appropriate and functional for developing nations where they can yield the available biological and medical information of new medications without compound investigation equipment and experiment.

In spite of the fact that there have been a few contributions on distance-based indices and degree-based indices, [6-9] the investigations of the topological index for certain uncommon structures 
are still to a great extent restricted. As a result of this, enormous scholarly and modern thinking has been pulled in to examine the topological indices of drug structures from a mathematical perspective.

Mathematical chemistry gives tools, for example, polynomials and numbers to obtain properties of chemical compounds without utilizing quantum mechanics. A topological index is a numerical parameter of a graph and describes its topology. It depicts the molecular structure numerically and is utilized in the advancement of qualitative structure activity relationships (QSARs). There are three kinds of topological indices:

1. degree-based.

2. distance-based.

3. spectral-based.

Degree-based topological indices have been studied extensively and can be correlated with many properties of the understudy molecular compounds. There is a strong relationship between distance-based and degree-based topological indices [10]. Topological indices are really the numerical values that relate the structure to different physical properties, synthetic reactivity, and organic biological activities [11-15]. Many properties, for example, heat of formation, boiling point, strain energy, rigidity, and fracture toughness of a molecule are strongly connected to its molecular graph.

Hosoya polynomial, (Wiener polynomial), [16] assumes an essential part in distance based topological indices. A considerable rundown of distance based indices can be effectively assessed from the Hosoya polynomial. A comparable leap forward was acquired as of late by Deutsch and Klavžar [17], with regards to degree-based indices. They presented M-polynomial in 2015 to assume a part, parallel to Hosoya polynomial, to decide on the closed form of numerous degree-based topological indices [18-22]. The genuine intensity of the M-polynomial is its extensive nature containing solid data about degree-based graph invariants. These invariants are graph based on symmetries displayed in the $2 \mathrm{~d}$-atomic grids and altogether explain a few properties of the material under perception.

A lot of research has been done in the direction of M-polynomial, for example Munir et al. computed M-polynomial and related indices of triangular boron nanotubes in [21], polyhex-nanotubes in [22], nanostar dendrimers in [18], titania nanotubes in [19], as well as M-Polynomials and topological indices of V-Phenylenic Nanotubes and Nanotori in [20]. In this paper we aim to compute the M-polynomial of the crystallographic structure of the molecule $\mathrm{Cu}_{2} \mathrm{O}$ and the crystal structure of titanium difluoride $\mathrm{T}_{\mathrm{i}} \mathrm{F}_{2}[n, m, t]$. We also recover the first and second Zagreb indices, the modified Zagreb index, the Symmetric division index, the Harmonic index, the Randić and the Inverse Randić index, the Augmented Zagreb index and the Inverse sum index for these molecules. We also plot our results to determine the dependence on the involved parameters. For more details about the topological indices and their applications, we refer to references [23-27].

\section{Basic Definitions and Literature Review}

Throughout this article, we assume $G$ to be a simple connected graph, $V(G)$ and $E(G)$ are the vertex set and the edge set respectively and $d_{v}$ denotes the degree of a vertex $v$.

Definition 1. The M-polynomial [17] of $G$ is defined as: $M(G, x, y)=\sum_{\delta \leq i \leq j \leq \Delta} m_{i j}(G) x^{i} y^{j}$ where $\delta=$ $\operatorname{Min}\left\{d_{v} \mid v \in V(G)\right\}, \Delta=\operatorname{Max}\left\{d_{v} \mid v \in V(G)\right\}$, and $m_{i j}(G)$ is the edge $v u \in E(G)$ such that where $i \leq j$.

Wiener index [28] is the first topological index and its various applications are discussed in $[29,30]$. Randić index, $R_{-1 / 2}(G)$, is introduced by Milan Randić in 1975 defined as: $R_{-1 / 2}(G)=\sum_{u v \in E(G)} \frac{1}{\sqrt{d_{u} d_{v}}}$.

For general details about $R_{-1 / 2}(G)$ and its generalized Randić index, $R_{\alpha}(G)=\sum_{u v \in E(G)} \frac{1}{\left(d_{u} d_{v}\right)^{\alpha}}$, please see [31-35]. 
The inverse Randić index is defined as $R R_{\alpha}(G)=\sum_{u v \in E(G)}\left(d_{u} d_{v}\right)^{\alpha}$. Clearly $R_{-1 / 2}(G)$ is a special case of $R_{\alpha}(G)$ when $\alpha=-\frac{1}{2}$. This index has many applications in diverse areas. Many papers and books such as [36-38] are written on this topological index as well. Gutman and Trinajstic introduced two indices namely the first Zagreb index and the second Zagreb index and are defined as: $M_{1}(G)=\sum_{u v \in E(G)}\left(d_{u}+d_{v}\right)$ and $M_{2}(G)=\sum_{u v \in E(G)}\left(d_{u} \times d_{v}\right)$. The second modified Zagreb index is defined as: ${ }^{m} M_{2}(G)=\sum_{u v \in E(G)} \frac{1}{d(u) d(v)}$. We refer [39-48] to the readers for comprehensive details of these indices. Other famous indices are the Symmetric division index: $\operatorname{SDD}(G)=\sum_{u v \in E(G)}\left\{\frac{\min \left(d_{u}, d_{v}\right)}{\max \left(d_{u}, d_{v}\right)}+\frac{\max \left(d_{u}, d_{v}\right)}{\min \left(d_{u}, d_{v}\right)}\right\}$, the Harmonic index: $H(G)=\sum_{v u \in E(G)} \frac{2}{d_{u}+d_{v}}$. Inverse sum index: $I(G)=\sum_{v u \in E(G)} \frac{d_{u} d_{v}}{d_{u}+d_{v}}$ and augmented Zagreb index: $A(G)=\sum_{v u \in E(G)}\left\{\frac{d_{u} d_{v}}{d_{u}+d_{v}-2}\right\}^{3},[49,50]$.

Table 1 presented in [7-9] relates some of these well-known degree-based topological indices with the M-polynomial with the following reserved notations

$$
\begin{aligned}
& D_{x}=x \frac{\partial(f(x, y))}{\partial x}, D_{y}=y \frac{\partial(f(x, y))}{\partial y}, S_{x}=\int_{0}^{x} \frac{f(t, y)}{t} d t, S_{y}=\int_{0}^{y} \frac{f(x, t)}{t} d t \\
& J(f(x, y))=f(x, x), Q_{\alpha}(f(x, y))=x^{\alpha} f(x, y) .
\end{aligned}
$$

Table 1. Derivation of some topological indices from the M-polynomial.

\begin{tabular}{cc}
\hline Topological Index & Derivation from $\boldsymbol{M}(G ; x, y)$ \\
\hline First Zagreb & $\left.\left(D_{x}+D_{y}\right)(M(G ; x, y))\right|_{x=y=1}$ \\
Second Zagreb & $\left.\left(D_{x} D_{y}\right)(M(G ; x, y))\right|_{x=y=1}$ \\
Second Modified Zagreb & $\left.\left(S_{x} S_{y}\right)(M(G ; x, y))\right|_{x=y=1}$ \\
General Randić & $\left.\left(D_{x}^{\alpha} D_{y}^{\alpha}\right)(M(G ; x, y))\right|_{x=y=1}$ \\
General Inverse Randi & $\left.\left(S_{x}^{\alpha} S_{y}^{\alpha}\right)(M(G ; x, y))\right|_{x=y=1}$ \\
Symmetric Division Index & $\left.\left(D_{x} S_{y}+S_{x} D_{y}\right)(M(G ; x, y))\right|_{x=y=1}$ \\
Harmonic Index & $2 S_{x} J(M(G ; x, y))_{x=1}$ \\
Inverse sum Index & $S_{x} J D_{x} D_{y}(M(G ; x, y))_{x=1}$ \\
\hline
\end{tabular}

\section{Methodology}

First of all we associated the graphs with $\mathrm{Cu}_{2} \mathrm{O}$ and $\mathrm{T}_{\mathrm{i}} \mathrm{F}_{2}[p, q, r]$ where atoms are represented by vertices and chemical bonds are represented by edges. Then by using the symmetry of the molecular structures of $\mathrm{Cu}_{2} \mathrm{O}$ and $\mathrm{T}_{\mathrm{i}} \mathrm{F}_{2}[p, q, r]$ we counted the edges and vertices by a simple counting method. By applying the formula of the polynomial we derived the $\mathrm{M}$-polynomials of $\mathrm{Cu}_{2} \mathrm{O}$ and $\mathrm{T}_{\mathrm{i}} \mathrm{F}_{2}[p, q, r]$. From these M-polynomials we recovered nine degree-based topological indices by using calculus. We used Maple 2015 to plot our results.

\section{Main Results}

\subsection{M-Polynomial and Degree-Based Topological Indices of $\mathrm{Cu}_{2} \mathrm{O}$}

Copper(I) oxide or cuprous oxide is the inorganic compound with the formula $\mathrm{Cu}_{2} \mathrm{O}$. It is one of the principal oxides of copper, the other being $\mathrm{CuO}$ or cupric oxide. The solid is diamagnetic. In terms of their coordination spheres, copper centers are 2-coordinated and the oxides are tetrahedral. The structure thus resembles in some sense the main polymorphs of $\mathrm{SiO}_{2}$, and both structures feature interpenetrated lattices. Copper(I) oxide dissolves in concentrated ammonia solution to form the colorless complex $\left[\mathrm{Cu}\left(\mathrm{NH}_{3}\right)_{2}\right]^{+}$, which is easily oxidized in air to the blue $\left[\mathrm{Cu}\left(\mathrm{NH}_{3}\right)_{4}\left(\mathrm{H}_{2} \mathrm{O}\right)_{2}\right]^{2+}$. It dissolves in hydrochloric acid to give solutions of $\mathrm{CuCl}_{2}{ }^{-}$. Dilute sulfuric acid and nitric acid 
produce copper(II) sulfate and copper(II) nitrate, respectively. Cuprous oxide is commonly used as a pigment, a fungicide, and an antifouling agent for marine paints. Rectifier diodes based on this material have been used industrially as early as 1924, long before silicon became the standard. Copper(I) oxide is also responsible for the pink color in a positive Benedict's test. This is the main reason to choose $\mathrm{Cu}_{2} \mathrm{O}$. Nowadays the Crystallographic Structure of the Molecule $\mathrm{Cu}_{2} \mathrm{O}$ has attracted attention due to its interesting properties, low-cost, abundance, non-toxic nature, and simple fabrication process [51]. The promising applications of $\mathrm{Cu}_{2} \mathrm{O}$ mainly focus on chemical sensors, solar cells, photocatalysis, lithium-ion batteries, and catalysis [52]. Figures 1-5 describe the graph of the molecule $\mathrm{Cu}_{2} \mathrm{O}$ [53]. The crystallographic structure of $\mathrm{Cu}_{2} \mathrm{O}$ is shown in Figure 1. In the lattice of $\mathrm{Cu}_{2} \mathrm{O}$ the structural characteristics of the atoms of $\mathrm{O}$ and $\mathrm{C}_{\mathrm{u}}$ are shown in Figure 2. By interpenetrating the $\mathrm{O}$ lattices with $\mathrm{Cu}$ lattices, $\mathrm{Cu}_{2} \mathrm{O}$ lattices are formed. The unit cell of $\mathrm{Cu}_{2} \mathrm{O}$ is shown in Figure 3. In Figure 3 copper atoms are shown by red dots and oxygen atoms are shown by blue dots. In the $\mathrm{Cu}_{2} \mathrm{O}$ lattice graph, each copper atom is attached to two oxygen atoms, and every oxygen atom is attached to four copper atoms. $\mathrm{Cu}_{2} \mathrm{O}[1,1,1]$ and $\mathrm{Cu}_{2} \mathrm{O}[2,3,3]$ are shown in Figures 4 and 5 respectively.

Let $G \cong \mathrm{Cu}_{2} \mathrm{O}[p, q, r]$ be the chemical graph of $\mathrm{Cu}_{2} \mathrm{O}$ with $p \times q$ unit cells in the plane and $\mathrm{r}$ layers [14]. It can be observed that

$$
\begin{gathered}
\left|V\left(\mathrm{Cu}_{2} \mathrm{O}[p, q, r]\right)\right|=6 p r r t+p q+q r+p r+q+p+r+1 \\
\left|E\left(C u_{2} \mathrm{O}[p, q, r]\right)\right|=8 p q r .
\end{gathered}
$$

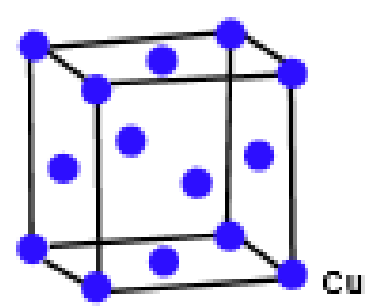

Figure 1. Crystallographic structure of $\mathrm{Cu}_{2} \mathrm{O}$.

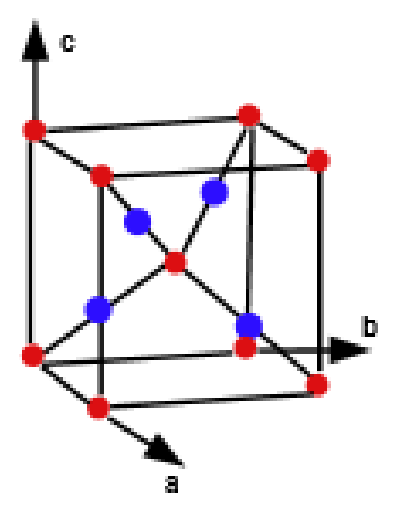

Figure 2. Formation of $\mathrm{Cu}_{2} \mathrm{O}$ lattices.

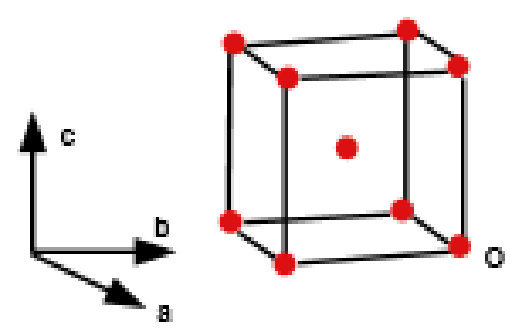

Figure 3. Unit cell of $\mathrm{Cu}_{2} \mathrm{O}$. 


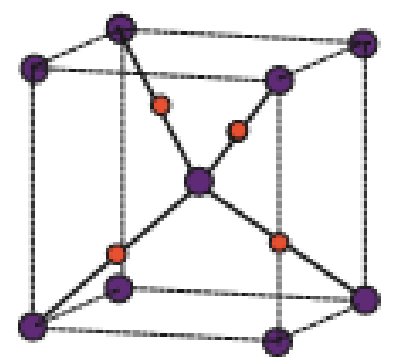

Figure 4. $\mathrm{Cu}_{2} \mathrm{O}[1,1,1]$.

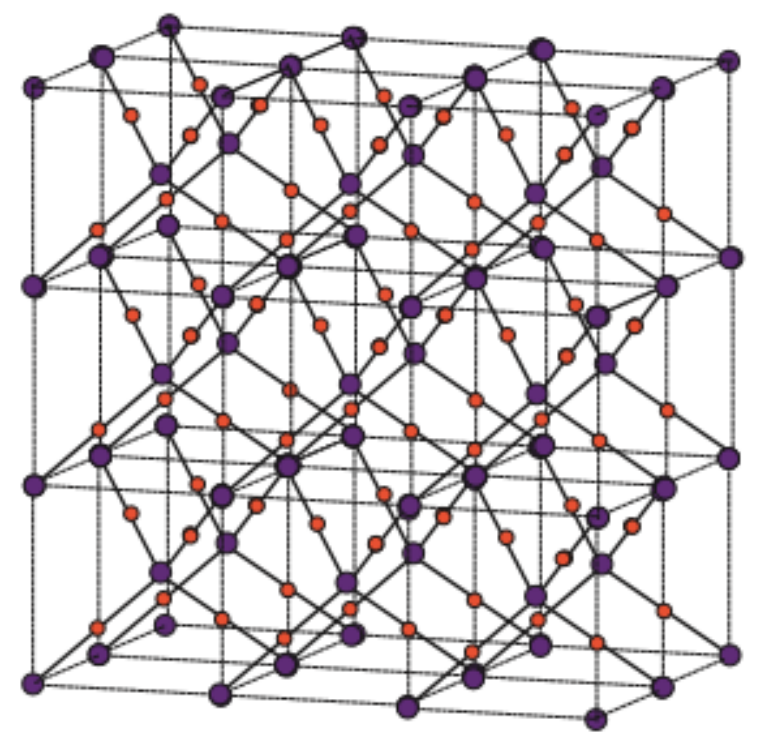

Figure 5. $\mathrm{Cu}_{2} \mathrm{O}[3,2,3]$.

Theorem 1. For the graph of crystallographic structure $G \cong \mathrm{Cu}_{2} \mathrm{O}[p, q, r]$, we have

$$
\begin{aligned}
M(G, x, y)= & 4(p+q+r-2) x y^{2}+4(p q+p r+q r-2(p+q+r)+3) x^{2} y^{2} \\
& +4(2 p q r-(p q+p r+q r)+p+q+r-1) x^{2} y^{4}
\end{aligned}
$$

Proof. Let $G$ be the crystallographic structure of $\mathrm{Cu}_{2} \mathrm{O}[p, q, r]$. The edge set of $\mathrm{Cu}_{2} \mathrm{O}[p, q, r]$ has the following three partitions,

$$
\begin{aligned}
& E_{1}=E_{\{1,2\}}=\left\{e=u v \in E(G) \mid d_{u}=1, d_{v}=2\right\}, \\
& E_{2}=E_{\{2,2\}}=\left\{e=u v \in E(G) \mid d_{u}=2, d_{v}=2\right\}, \\
& E_{3}=E_{\{2,4\}}=\left\{e=u v \in E(G) \mid d_{u}=2, d_{v}=4\right\},
\end{aligned}
$$

such that

$$
\left|E_{1}(G)\right|=4 p+4 q+4 r-8
$$

$\left|E_{2}(G)\right|=4 p q+4 p r+4 q r-8 p-8 q-8 r+12$.

$\left|E_{3}(G)\right|=4(2 p q r-p q-p r-q r+p+q+r-1)$. 
Thus the M-polynomial of $\mathrm{Cu}_{2} \mathrm{O}[n, m, t]$ is

$$
\begin{aligned}
M(G ; x, y)= & \sum_{i \leq j} m_{i j}(G) x^{i} y^{j} \\
= & \sum_{1 \leq 2} m_{12}(G) x y^{2}+\sum_{2 \leq 2} m_{22}(G) x^{2} y^{2}+\sum_{2 \leq 4} m_{24}(G) x^{2} y^{4} \\
= & \sum_{u v \in E_{1}} m_{12}(G) x y^{2}+\sum_{u v \in E_{2}} m_{22}(G) x^{2} y^{2}+\sum_{u v \in E_{3}} m_{24}(G) x^{2} y^{4} \\
= & \left|E_{1}(G)\right| x y^{2}+\left|E_{2}(G)\right| x^{2} y^{2}+\left|E_{3}(G)\right| x^{2} y^{4} \\
= & (4 p+4 q+4 r-8) x y^{2}+(4 p q+4 p r+4 q r-8 p-8 q-8 r+12) x^{2} y^{2} \\
& +4(2 p q r-p q-p r-q r+p+q+r-1) x^{2} y^{4} . \\
= & 4(p+q+r-2) x y^{2}+4(p q+p r+q r-2(p+q+r)+3) x^{2} y^{2} \\
& +4(2 p q r-(p q+p r+q r)+p+q+r-1) x^{2} y^{4} .
\end{aligned}
$$

Theorem 2. For the graph of the crystallographic structure $\mathrm{G}=\mathrm{Cu}_{2} \mathrm{O}[p, q, r]$, we have

$$
M_{1}(G)=48 p q r-8(p q+p r+q r)+4(p+q+r)
$$

Proof. Let

$$
\begin{aligned}
M(G, x, y)= & f(x, y)=4(p+q+r-2) x y^{2}+4(p q+p r+q r-2(p+q+r)+3) x^{2} y^{2} \\
& +4(2 p q r-(p q+p r+q r)+p+q+r-1) x^{2} y^{4}
\end{aligned}
$$

Then

$$
\begin{aligned}
D_{x} f(x, y)= & 4(p+q+r-2) x y^{2}+8(p q+p r+q r-2(p+q+r)+3) x^{2} y^{2} \\
& +8(2 p q r-(p q+p r+q r)+p+q+r-1) x^{2} y^{4} \\
D_{y} f(x, y)= & 8(p+q+r-2) x y^{2}+8(p q+p r+q r-2(p+q+r)+3) x^{2} y^{2} \\
& +16(2 p q r-(p q+p r+q r)+p+q+r-1) x^{2} y^{4}
\end{aligned}
$$

From Table 1, Equations (2) and (3)

$$
\begin{aligned}
M_{1}(G) & =\left.\left(D_{x}+D_{y}\right) f(x, y)\right|_{x=y=1} \\
& =48 p q r-8(p q+p r+q r)+4(p+q+r) .
\end{aligned}
$$

The following Figure 6 is a 3D plot of the first Zagreb index (for $p=1$ left, $q=1$ middle and $r=1$ right) and tells us the dependence of the first Zagreb index on the involved parameters.
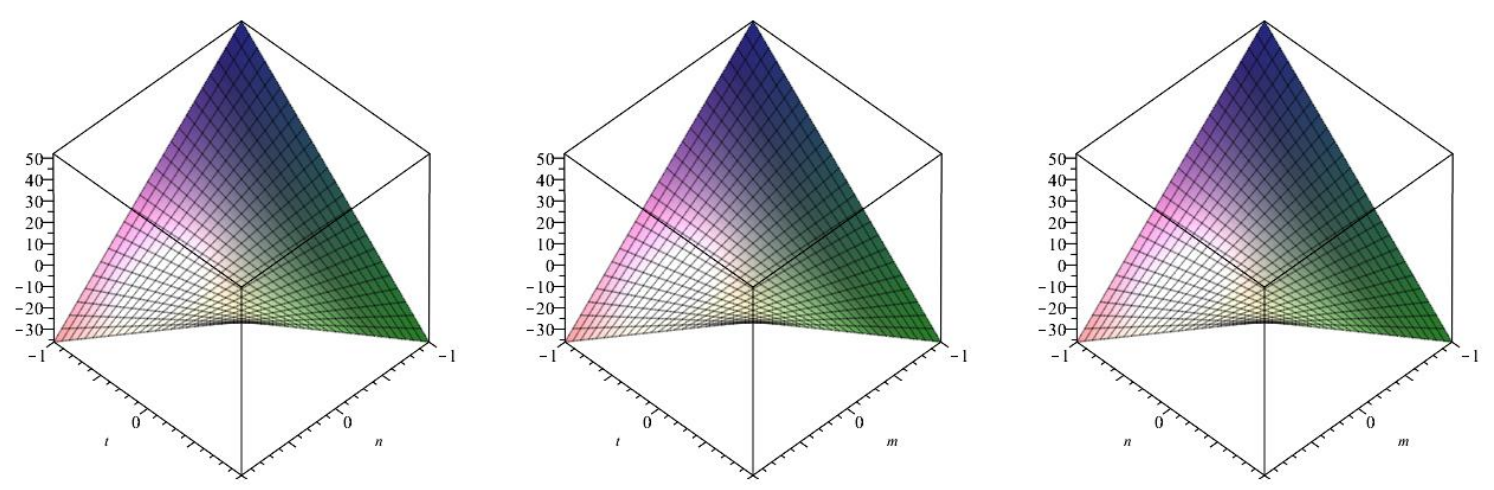

Figure 6. 3D plot of first Zagreb index. 
Theorem 3. For the graph of the crystallographic structure $\mathrm{G}=\mathrm{Cu}_{2} \mathrm{O}[p, q, r]$, we have

$$
M_{2}(G)=64 p q r-16(p q+p r+q r)+8(p+q+r) .
$$

Proof. Let

$$
\begin{aligned}
M(G, x, y)= & 4(p+q+r-2) x y^{2}+4(p q+p r+q r-2(p+q+r)+3) x^{2} y^{2} \\
& +4(2 p q r-(p q+p r+q r)+p+q+r-1) x^{2} y^{4}
\end{aligned}
$$

Then

$$
\begin{aligned}
D_{y} D_{x} f(x, y) & =8(p+q+r-2) x y^{2}+16(p q+p r+q r-2(p+q+r)+3) x^{2} y^{2} \\
& +32(2 p q r-(p q+p r+q r)+p+q+r-1) x^{2} y^{4}
\end{aligned}
$$

Now from Table 1 and Equation (4)

$$
\begin{aligned}
M_{2}(G) & =\left.D_{y} D_{x}(f(x, y))\right|_{x=y=1} \\
& =64 p q r-16(p q+p q+q r)+8(p+q+r) .
\end{aligned}
$$

The following Figure 7 is a 3D plot of the second Zagreb index (for $p=1$ left, $q=1$ middle and $r=1$ right) and tells us the dependence of the second Zagreb index on the involved parameters.
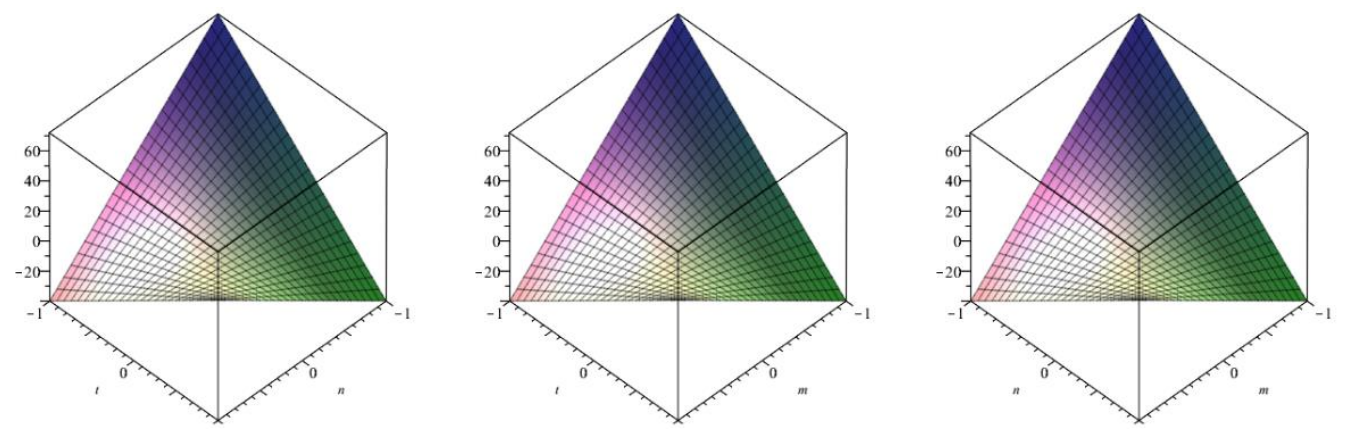

Figure 7. 3D plot of second Zagreb index.

Theorem 4. For the graph of the crystallographic structure $\mathrm{G}=\mathrm{Cu}_{2} \mathrm{O}[p, q, r]$, we have

$$
{ }^{m} M_{2}(G)=p q r+\frac{1}{2}(p q+p r+q r)+\frac{1}{2}(p+q+r)-\frac{3}{2} .
$$

Proof. Let

$$
\begin{aligned}
M(G, x, y)= & 4(p+q+r-2) x y^{2}+4(p q+p r+q r-2(p+q+r)+3) x^{2} y^{2} \\
& +4(2 p q r-(p q+p r+q r)+p+q+r-1) x^{2} y^{4}
\end{aligned}
$$

Then

$$
\begin{aligned}
S_{x} S_{y}(f(x, y))= & 2(p+q+r-2) x y^{2}+(p q+p r+q r-2(p+q+r)+3) x^{2} y^{2} \\
& +\frac{1}{2}(2 p q r-(p q+p r+q r)+p+q+r-1) x^{2} y^{4},
\end{aligned}
$$

Now from Table 1 and Equation (5)

$$
\begin{aligned}
{ }^{m} M_{2}(G) & =\left.S_{x} S_{y}(f(x, y))\right|_{x=y=1} \\
& =p q r+\frac{1}{2}(p q+p r+q r)+\frac{1}{2}(p+q+r)-\frac{3}{2} .
\end{aligned}
$$


The following Figure 8 is a 3D plot of the modified second Zagreb index (for $p=1$ left, $q=1$ middle and $r=1$ right) and tells us the dependence of the modified second Zagreb index on the involved parameters.
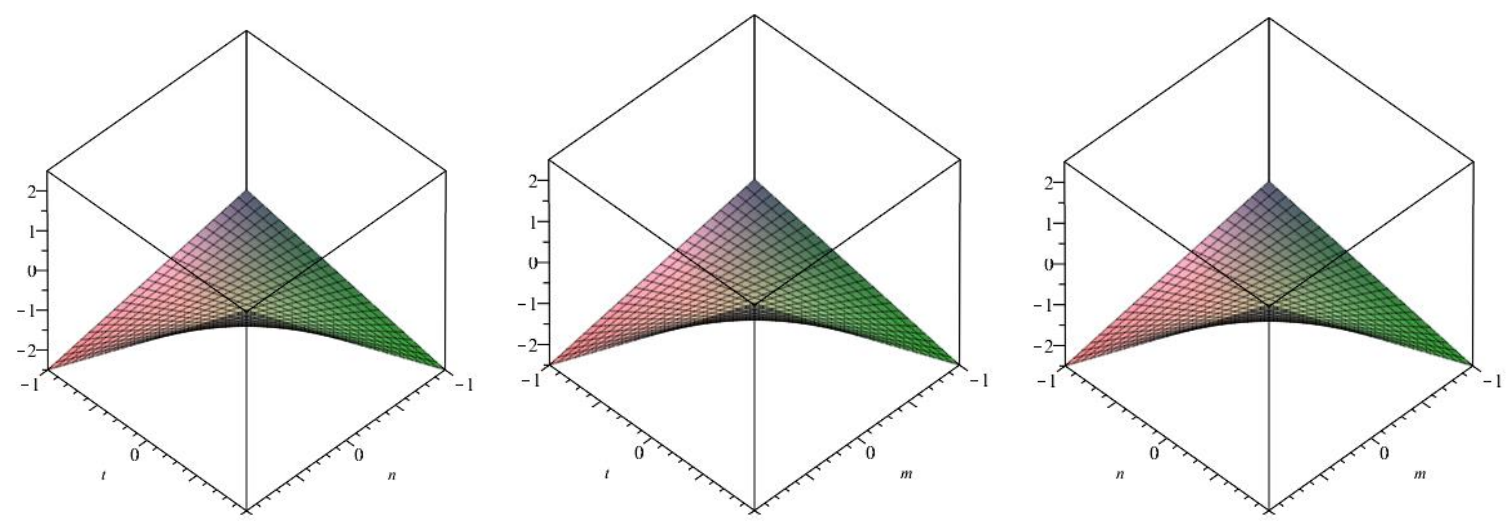

Figure 8. 3D plot of modified second Zagreb index.

Theorem 5. For the graph of the crystallographic structure $\mathrm{G}=\mathrm{Cu}_{2} \mathrm{O}[p, q, r]$, we have

$$
R_{\alpha}(G)=2^{3 \alpha+3} p q r+\left(2^{2 \alpha+2}-2^{3 \alpha+2}\right)(p q+p r+q r)+\left(2^{\alpha+2}-2^{2 \alpha+3}+2^{3 \alpha+2}\right)(p+q+r)-\left(2^{\alpha+3}-3 \cdot 2^{2 \alpha+2}+2^{3 \alpha+2}\right)
$$

Proof. Let

$$
\begin{aligned}
M(G, x, y)= & 4(p+q+r-2) x y^{2}+4(p q+p r+q r-2(p+q+r)+3) x^{2} y^{2} \\
& +4(2 p q r-(p q+p r+q r)+p+q+r-1) x^{2} y^{4}
\end{aligned}
$$

Then

$$
\begin{aligned}
D_{x}{ }^{\alpha} D_{y}{ }^{\alpha}(f(x, y))= & 2^{\alpha+2}(p+q+r-2) x y^{2}+2^{2 \alpha+2}(p q+p r+q r-2(p+q+r)+3) x^{2} y^{2} \\
& +2^{3 \alpha+2}(2 p q r-(p q+p r+q r)+p+q+r-1) x^{2} y^{4},
\end{aligned}
$$

Now from Table 1 and Equation (6)

$$
\begin{aligned}
& R_{\alpha}(G)=\left.D_{x}^{\alpha} D_{y}^{\alpha}(f(x, y))\right|_{x=y=1} \\
& =2^{3 \alpha+3} p q r+\left(2^{2 \alpha+2}-2^{3 \alpha+2}\right)(p q+p r+q r)+\left(2^{\alpha+2}-2^{2 \alpha+3}+2^{3 \alpha+2}\right)(p+q+r)-\left(2^{\alpha+3}-3 \cdot 2^{2 \alpha+2}+2^{3 \alpha+2}\right) .
\end{aligned}
$$

The following Figure 9 is a 3D plot of the Randić index (for $p=1$ left, $q=1$ middle and $r=1$ right) and tells us the dependence of the Randić index on the involved parameters. 

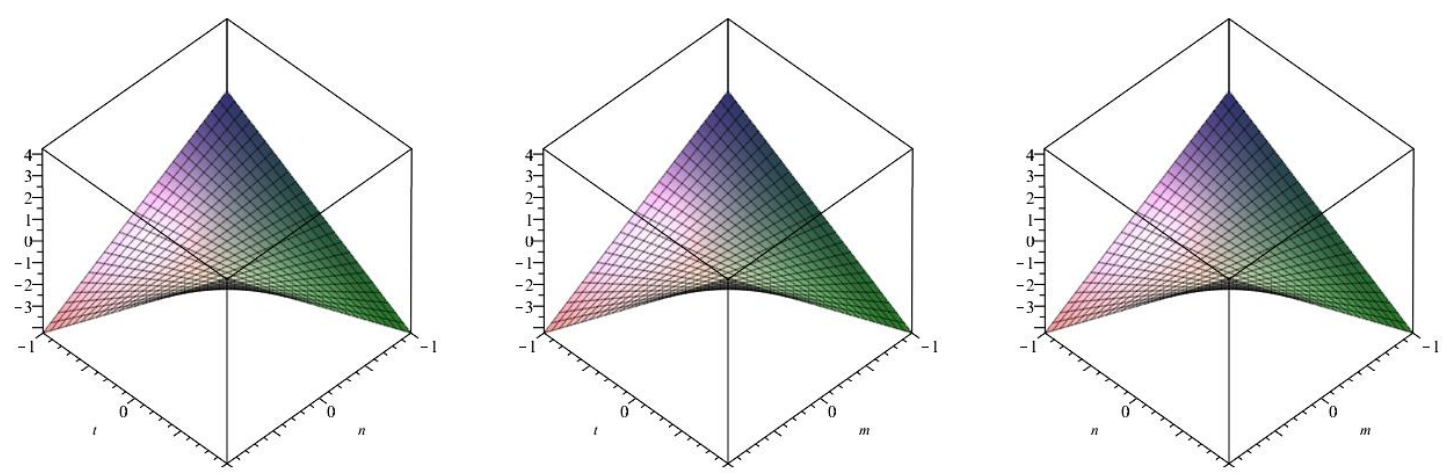

Figure 9. 3D plot of Randić index.

Theorem 6. For the graph of the crystallographic structure $\mathrm{G}=\mathrm{Cu}_{2} \mathrm{O}[p, q, r]$, we have

$$
R R_{\alpha}(G)=\frac{1}{2^{3 \alpha-3}} p q r+\left(\frac{1}{2^{2 \alpha-2}}-\frac{1}{2^{3 \alpha-2}}\right)(p q+p r+q r)+\left(\frac{1}{2^{\alpha-2}}-\frac{1}{2^{2 \alpha-3}}+\frac{1}{2^{3 \alpha-2}}\right)(p+q+r)-\left(\frac{1}{2^{\alpha-3}}-\frac{3}{2^{2 \alpha-2}}+\frac{1}{2^{3 \alpha-2}}\right) .
$$

Proof. Let

$$
\begin{aligned}
M(G, x, y)= & 4(p+q+r-2) x y^{2}+4(p q+p r+q r-2(p+q+r)+3) x^{2} y^{2} \\
& +4(2 p q r-(p q+p r+q r)+p+q+r-1) x^{2} y^{4}
\end{aligned}
$$

Then

$$
\begin{aligned}
S_{x}{ }^{\alpha} S_{y}{ }^{\alpha}(f(x, y))= & \frac{1}{2^{\alpha-2}}(p+q+r-2) x y^{2}+\frac{1}{2^{2 \alpha-2}}(p q+p r+q r-2(p+q+r)+3) x^{2} y^{2} \\
& +\frac{1}{2^{3 \alpha-2}}(2 p q r-(p q+p r+q r)+p+q+r-1) x^{2} y^{4}
\end{aligned}
$$

Now from Table 1 and Equation (7)

$$
\begin{aligned}
& R R_{\alpha}(G)=\left.S_{x}^{\alpha} S_{y}^{\alpha}(f(x, y))\right|_{x=y=1} \\
& =\frac{1}{2^{3 \alpha-3}} p q r+\left(\frac{1}{2^{2 \alpha-2}}-\frac{1}{2^{3 \alpha-2}}\right)(p q+p r+q r)+\left(\frac{1}{2^{\alpha-2}}-\frac{1}{2^{2 \alpha-3}}+\frac{1}{2^{3 \alpha-2}}\right)(p+q+r)-\left(\frac{1}{2^{\alpha-3}}-\frac{3}{2^{2 \alpha-2}}+\frac{1}{2^{3 \alpha-2}}\right) .
\end{aligned}
$$

The following Figure 10 is a 3D plot of the inverse Randić index (for $p=1$ left, $q=1$ middle and $r=1$ right) and tells us the dependence of the inverse Randić index on the involved parameters.
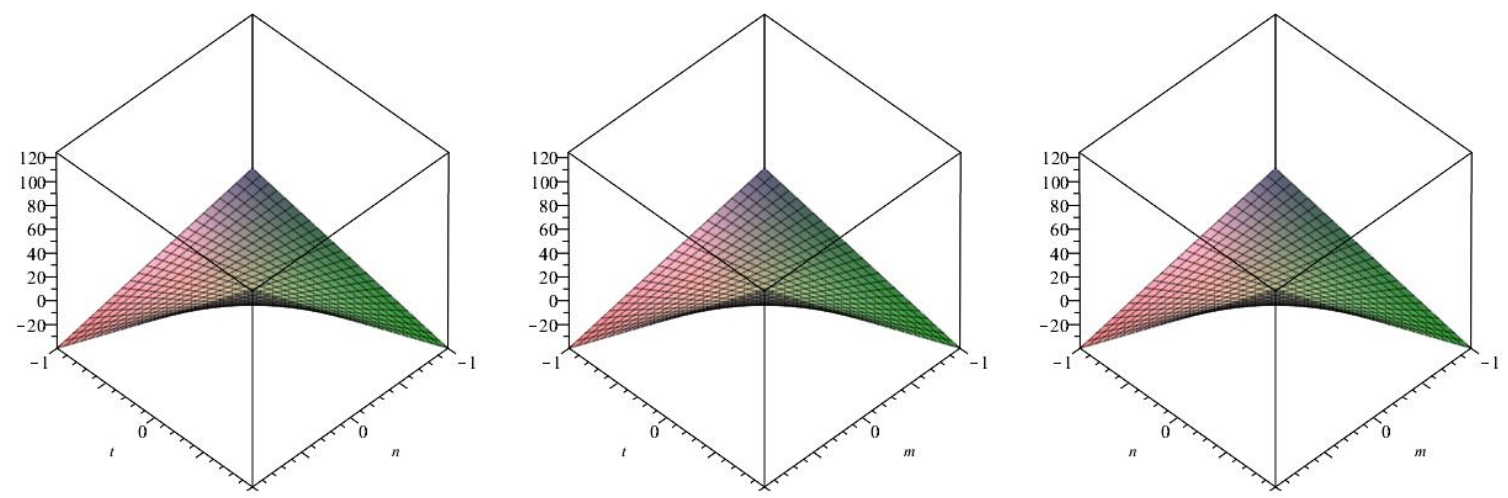

Figure 10. 3D plot of Inverse Randić index. 
Theorem 7. For the graph of the crystallographic structure $\mathrm{G}=\mathrm{Cu}_{2} \mathrm{O}[p, q, r]$, we have

$$
S S D(G)=20 p q r-2(p q+p r+q r)+4(p+q+r)-6 .
$$

Proof. Let

$$
\begin{aligned}
M(G, x, y)= & 4(p+q+r-2) x y^{2}+4(p q+p r+q r-2(p+q+r)+3) x^{2} y^{2} \\
& +4(2 p q r-(p q+p r+q r)+p+q+r-1) x^{2} y^{4}
\end{aligned}
$$

Then

$$
\begin{aligned}
S_{y} D_{x}(f(x, y))= & 2(p+q+r-2) x y^{2}+4(p q+p r+q r-2(p+q+r)+3) x^{2} y^{2} \\
& +2(2 p q r-(p q+p r+q r)+p+q+r-1) x^{2} y^{4}, \\
S_{x} D_{y}(f(x, y))= & 8(p+q+r-2) x y^{2}+4(p q+p r+q r-2(p+q+r)+3) x^{2} y^{2} \\
& +8(2 p q r-(p q+p r+q r)+p+q+r-1) x^{2} y^{4},
\end{aligned}
$$

Now from Table 1, Equations (8) and (9)

$$
\begin{aligned}
S S D(G) & =\left.\left(S_{y} D_{x}+S_{x} D_{y}\right)(f(x, y))\right|_{x=y=1} \\
& =20 p q r-2(p q+p r+q r)+4(p+q+r)-6 .
\end{aligned}
$$

The following Figure 11 is a 3D plot of the Symmetric division index (for $p=1$ left, $q=1$ middle and $r=1$ right) and tells us the dependence of the Symmetric division index on the involved parameters.
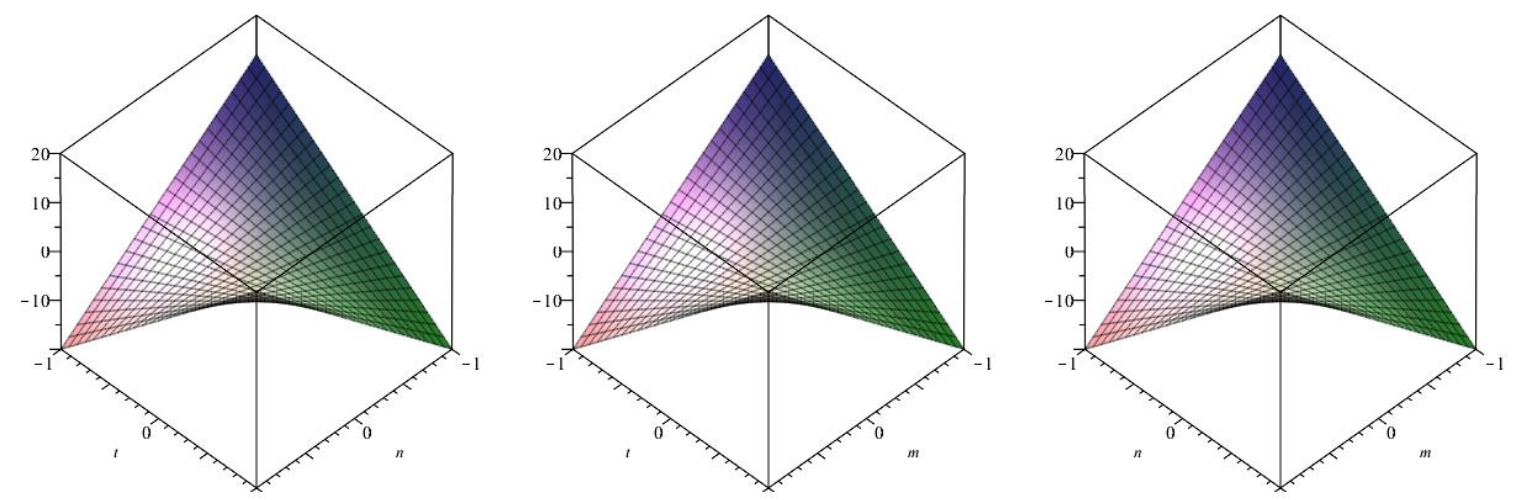

Figure 11. 3D plot of Symmetric division index.

Theorem 8. For the graph of the crystallographic structure $\mathrm{G}=\mathrm{Cu}_{2} \mathrm{O}[p, q, r]$, we have

$$
H(G)=\frac{8}{3} p q r+\frac{2}{3}(p q+p r+q r)-\frac{2}{3}
$$

Proof. Let

$$
\begin{aligned}
M(G, x, y)= & 4(p+q+r-2) x y^{2}+4(p q+p r+q r-2(p+q+r)+3) x^{2} y^{2} \\
& +4(2 p q r-(p q+p r+q r)+p+q+r-1) x^{2} y^{4}
\end{aligned}
$$

Then

$$
\begin{aligned}
S_{x} J f(x, y)= & \frac{4}{3}(p+q+r-2) x y^{2}+(p q+p r+q r-2(p+q+r)+3) x^{2} y^{2} \\
& +\frac{2}{3}(2 p q r-(p q+p r+q r)+p+q+r-1) x^{2} y^{4}
\end{aligned}
$$


Now using Table 1 and Equation (10)

$$
\begin{aligned}
H(G) & =\left.2 S_{x} J(f(x, y))\right|_{x=1} \\
& =\frac{8}{3} p q r+\frac{2}{3}(p q+p r+q r)-\frac{2}{3} .
\end{aligned}
$$

The following Figure 12 is a 3D plot of the Harmonic index (for $p=1$ left, $q=1$ middle and $r=1$ right) and tells us the dependence of the Harmonic index on the involved parameters.
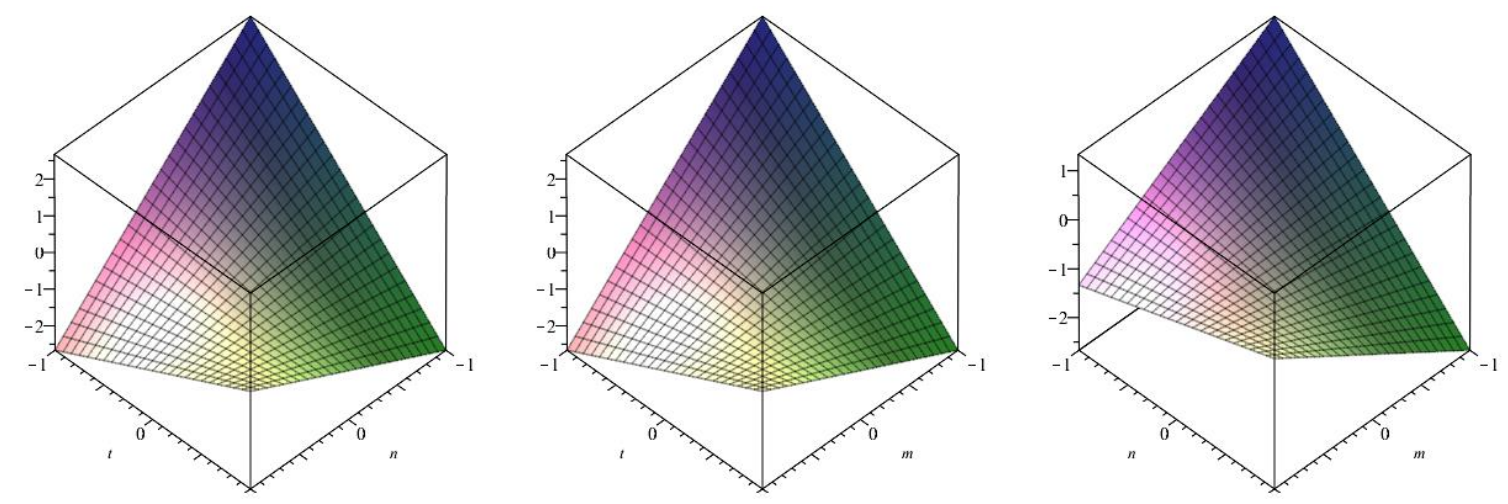

Figure 12. 3D plot of Harmonic index.

Theorem 9. For the graph of crystallographic structure $\mathrm{G}=\mathrm{Cu}_{2} \mathrm{O}[p, q, r]$, we have

$$
I(G)=\frac{32}{3} p q r-\frac{4}{3}(p q+p r+q r)+\frac{4}{3} .
$$

Proof. Let

$$
\begin{aligned}
M(G, x, y)= & 4(p+q+r-2) x y^{2}+4(p q+p r+q r-2(p+q+r)+3) x^{2} y^{2} \\
& +4(2 p q r-(p q+p r+q r)+p+q+r-1) x^{2} y^{4}
\end{aligned}
$$

Then

$$
\begin{aligned}
S_{x} J D_{x} D_{y} f(x, y)= & \frac{8}{3}(p+q+r-2) x y^{2}+4(p q+p r+q r-2(p+q+r)+3) x^{2} y^{2} \\
& +\frac{16}{3}(2 p q r-(p q+p r+q r)+p+q+r-1) x^{2} y^{4}
\end{aligned}
$$

Now using Table 1 and Equation (11), we get

$$
\begin{aligned}
I(G) & =S_{x} J D_{x} D_{y}(f(x, y))_{x=1} \\
& =\frac{32}{3} p q r-\frac{4}{3}(p q+p r+q r)+\frac{4}{3} .
\end{aligned}
$$

The following Figure 13 is a 3D plot of the Inverse sum index (for $p=1$ left, $q=1$ middle and $r=1$ right) and tells us the dependence of the Inverse sum index on the involved parameters. 

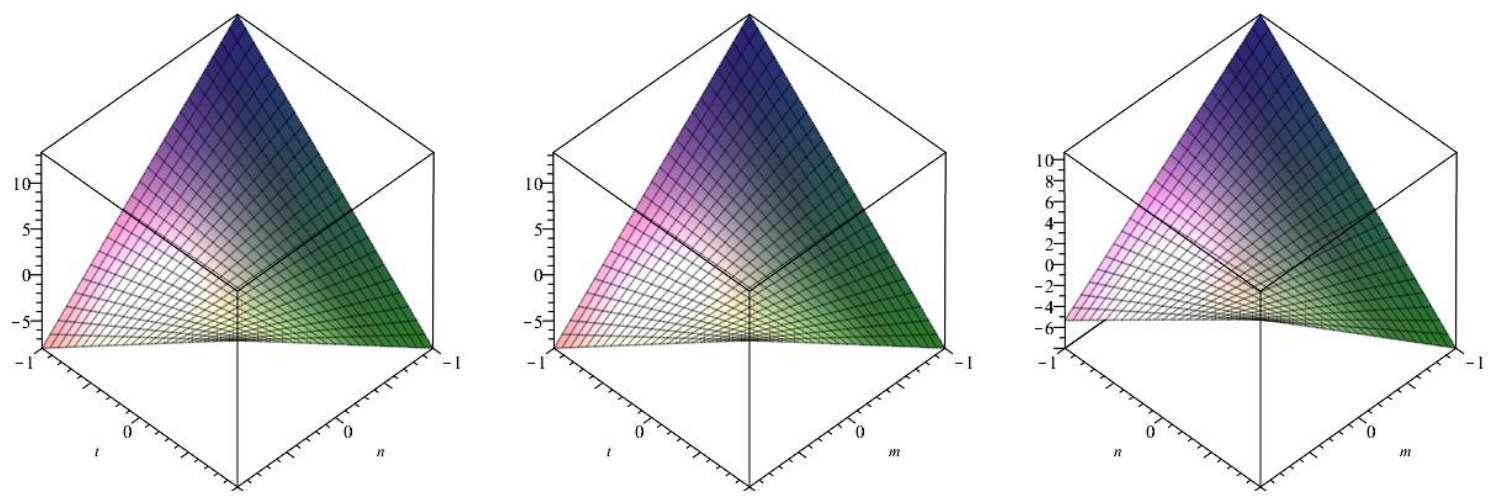

Figure 13. 3D plot of Inverse sum index.

Theorem 10. For the graph of the crystallographic structure $\mathrm{G}=\mathrm{Cu}_{2} \mathrm{O}[p, q, r]$, we have

$$
A(G)=64 p q r
$$

Proof. Let

$$
\begin{aligned}
M(G, x, y)= & 4(p+q+r-2) x y^{2}+4(p q+p r+q r-2(p+q+r)+3) x^{2} y^{2} \\
& +4(2 p q r-(p q+p r+q r)+p+q+r-1) x^{2} y^{4}
\end{aligned}
$$

Then

$$
\begin{aligned}
S_{x}{ }^{3} Q_{-2} J D_{x}{ }^{3} D_{y}{ }^{3} f(x, y)= & 32(p+q+r-2) x y^{2}+32(p q+p r+q r-2(p+q+r)+3) x^{2} y^{2} \\
& +\frac{2048}{64}(2 p q r-(p q+p r+q r)+p+q+r-1) x^{2} y^{4} .
\end{aligned}
$$

Using Table 1 and Equation (12), we get

$$
\begin{aligned}
A(G) & =\left.S_{x}{ }^{3} Q_{-2} J D_{x}{ }^{3} D_{y}{ }^{3}(f(x, y))\right|_{x=1} \\
& =64 \text { pqr. }
\end{aligned}
$$

The following Figure 14 is a 3D plot of the Augmented Zagreb index (for $p=1$ left, $q=1$ middle and $r=1$ right) and tells us the dependence of the Augmented Zagreb index on the involved parameters.
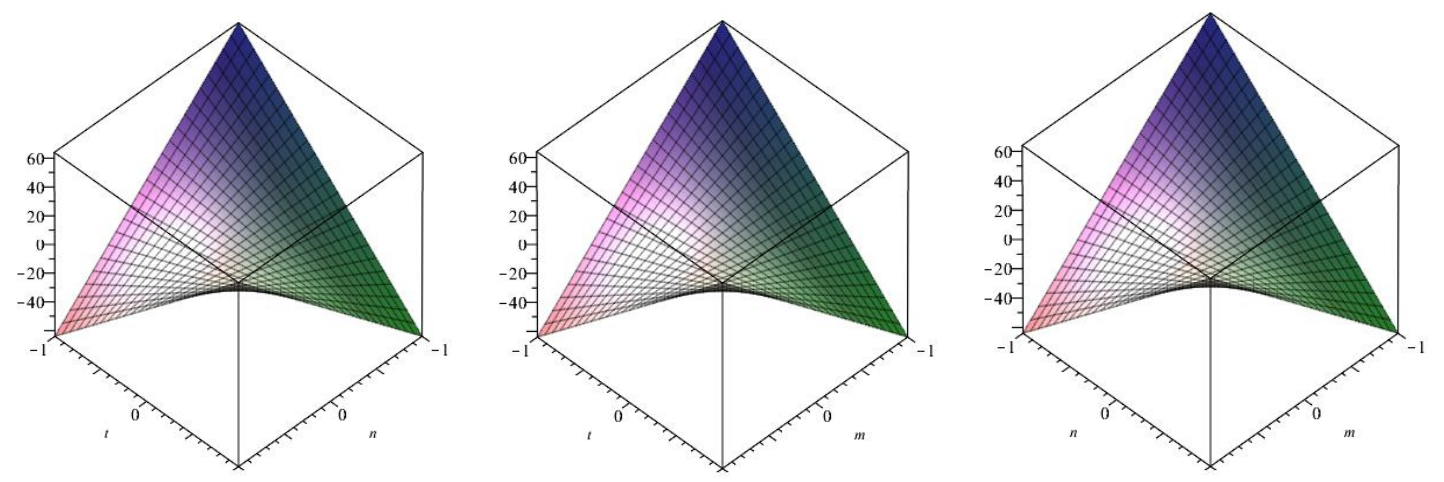

Figure 14. 3D plot of Augmented Zagreb index. 


\subsection{Polynomial and Degree-Based Topological Indices for $T_{i} F_{2}[p, q, r]$}

Titanium difluoride is a water-insoluble titanium hotspot for use in oxygen-delicate applications, for example, metal generation. Fluoride mixes have assorted applications in current advancements and science, from oil refining and carving to engineered natural science and the production of pharmaceuticals. The graph associated with $\mathrm{T}_{\mathrm{i}} \mathrm{F}_{2}[p, q, r]$ is given in Figure 3, see [54]. Let $G$ be the chemical graph of $\mathrm{T}_{\mathrm{i}} \mathrm{F}_{2}[p, q, r]$ with $\mathrm{p} \times \mathrm{q}$ unit cells in the plane and $t$ layers [23]. In Figures 15 and 16, red dots are for $\mathrm{F}$ atoms and green dots are for $\mathrm{T}_{\mathrm{i}}$ atoms. Now it can be observed easily from Figures 15 and 16 that

$$
\begin{aligned}
\left|V\left(T_{i} F_{2}[p, q, r]\right)\right|= & 12 p q r+2 p q+2 p r+2 q r+p+q+r+1 \\
& \left|E\left(T_{i} F_{2}[p, q, r]\right)\right|=32 p q r .
\end{aligned}
$$

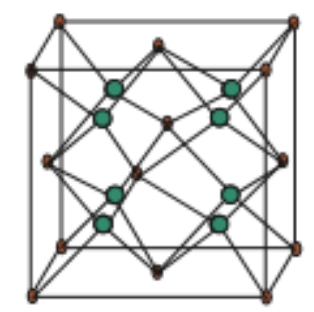

Figure 15. $\mathrm{T}_{\mathrm{i}} \mathrm{F}_{2}[1,1,1]$.

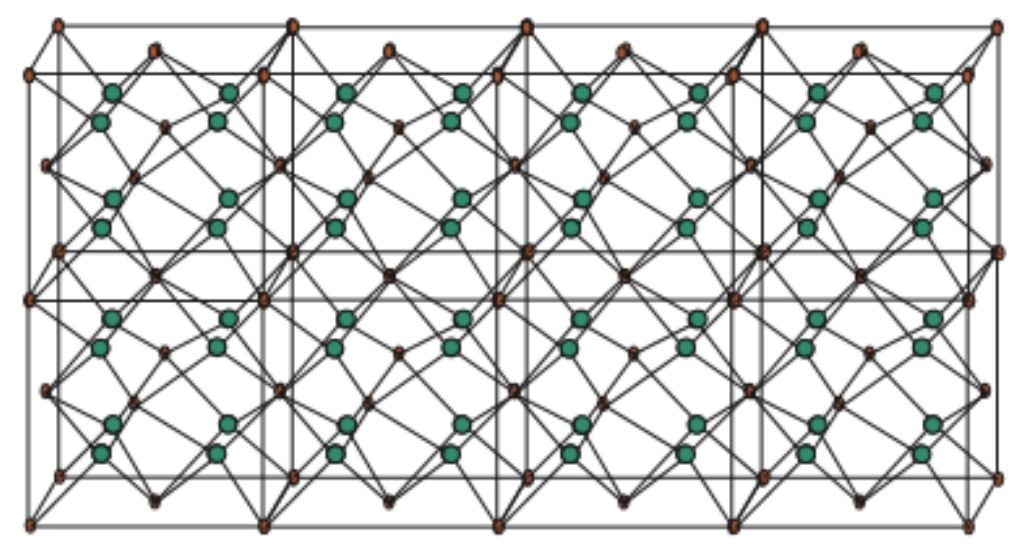

Figure 16. $\mathrm{T}_{\mathrm{i}} \mathrm{F}_{2}[4,1,2]$.

Theorem 11. For the crystal structure of titanium difluoride $G=T_{i} F_{2}[p, q, r]$, we have

$$
\begin{aligned}
M(G, x, y) & =8 x y^{4}+8(p+q+r-3) x^{2} y^{4}+[16(p q+p r+q r)-16(p+q+r)+24] x^{4} y^{4} \\
& +[32 p q r-16(p q+p r+q r)+8(p+q+r)-8] x^{4} y^{8} .
\end{aligned}
$$

Proof. The edge set of $G=\mathrm{T}_{\mathrm{i}} \mathrm{F}_{2}[p, q, r]$ has the following four partitions,

$$
\begin{aligned}
& E_{1}=E_{\{1,4\}}=\left\{e=u v \in E(G) \mid d_{u}=1, d_{v}=4\right\}, \\
& E_{2}=E_{\{2,4\}}=\left\{e=u v \in E(G) \mid d_{u}=2, d_{v}=4\right\}, \\
& E_{3}=E_{\{4,4\}}=\left\{e=u v \in E(G) \mid d_{u}=d_{v}=4\right\}, \\
& E_{4}=E_{\{4,8\}}=\left\{e=u v \in E(G) \mid d_{u}=4, d_{v}=8\right\},
\end{aligned}
$$

such that

$$
\left|E_{1}(G)\right|=8
$$




$$
\begin{gathered}
\left|E_{2}(G)\right|=8(p+q+r-3), \\
\left|E_{3}(G)\right|=16(p q+p r+q r)-16(p+q+r)+24 . \\
\left|E_{4}(G)\right|=32 p q r-16(p q+p r+q r)+8(p+q+r)-8 .
\end{gathered}
$$

Thus the M-polynomial of $T_{i} F_{2}[p, q, r]$ is:

$$
\begin{aligned}
M(G ; x, y) & =\sum_{i \leq j} m_{i j}(G) x^{i} y^{j} \\
& =\sum_{1 \leq 4} m_{14}(G) x y^{4}+\sum_{2 \leq 4} m_{24}(G) x^{2} y^{4}+\sum_{4 \leq 4} m_{44}(G) x^{4} y^{4}+\sum_{4 \leq 8} m_{48}(G) x^{4} y^{8} \\
& =\sum_{u v \in E_{1}} m_{14}(G) x y^{4}+\sum_{u v \in E_{2}} m_{24}(G) x^{2} y^{4}+\sum_{u v \in E_{3}} m_{44}(G) x^{4} y^{4}+\sum_{u v \in E_{4}} m_{48}(G) x^{4} y^{8} \\
& =\left|E_{1}(G)\right| x y^{4}+\left|E_{2}(G)\right| x^{2} y^{4}+\left|E_{3}(G)\right| x^{4} y^{4}+\left|E_{4}(G)\right| x^{4} y^{8} \\
& =8 x y^{4}+8(p+q+r-3) x^{2} y^{4}+[16(p q+p r+q r)-16(p+q+r)+24] x^{4} y^{4} \\
& +[32 p q r-16(p q+p r+q r)+8(p+q+r)-8] x^{4} y^{8} .
\end{aligned}
$$

Now we compute some indices by applying fundamental calculus results on the M-polynomial. The proofs of Theorems 12 to 20 are the same as Theorems 2 to 10 .

Theorem 12. For the crystal structure of titanium difluoride $G=T_{i} F_{2}[p, q, r]$, we have

$$
M_{1}(G)=384 p q r-64(p q+p r+q r)+16(p+q+r)-8 .
$$

Theorem 13. For the crystal structure of titanium difluoride $G=T_{i} F_{2}[p, q, r]$, we have

$$
M_{2}(G)=1024 p q r-256(p q+p r+q r)+64(p+q+r)-64 .
$$

Theorem 14. For the crystal structure of titanium difluoride $G=T_{i} F_{2}[p, q, r]$, we have

$$
{ }^{m} M_{2}(G)=p q r+\frac{1}{2}(p q+p r+q r)+\frac{1}{4}(p+q+r)+\frac{1}{4} .
$$

Theorem 15. For the crystal structure of titanium difluoride $G=T_{i} F_{2}[p, q, r]$, we have

$$
R_{\alpha}(G)=2^{5 \alpha+5} p q r+\left(2^{4 \alpha+4}-2^{5 \alpha+4}\right)(p q+p r+q r)+\left(2^{3 \alpha+3}-2^{4 \alpha+4}+2^{5 \alpha+3}\right)(p+q+r)+\left(2^{2 \alpha+3}-3 \cdot 2^{3 \alpha+3}+3 \cdot 2^{4 \alpha+3}-2^{5 \alpha+3}\right) .
$$

Theorem 16. For the crystal structure of titanium difluoride $G=T_{i} F_{2}[p, q, r]$, we have $R R_{\alpha}(G)=\frac{1}{2^{5 \alpha-5}} p q r+\left(\frac{1}{2^{4 \alpha-4}}-\frac{1}{2^{5 \alpha-4}}\right)(p q+p r+q r)+\left(\frac{1}{2^{3 \alpha-3}}-\frac{1}{2^{4 \alpha-4}}+\frac{1}{2^{5 \alpha-3}}\right)(p+q+r)+\left(\frac{1}{2^{2 \alpha-3}}-\frac{3}{2^{3 \alpha-3}}+\frac{3}{2^{4 \alpha-3}}-\frac{1}{2^{5 \alpha-3}}\right)$.

Theorem 17. For the crystal structure of titanium difluoride $G=T_{i} F_{2}[p, q, r]$, we have

$$
S S D(G)=80 p q r-8(p q+p r+q r)+8(p+q+r)+2 .
$$

Theorem 18. For the crystal structure of titanium difluoride $G=T_{i} F_{2}[p, q, r]$, we have

$$
H(G)=\frac{16}{3} p q r-\frac{4}{3}(p q+p r+q r)-\frac{2}{15} .
$$


Theorem 19. For the crystal structure of titanium difluoride $G=T_{i} F_{2}[p, q, r]$, we have

$$
I(G)=\frac{256}{3} p q r-\frac{32}{3}(p q+p r+q r)+\frac{16}{15}
$$

Theorem 20. For the crystal structure of titanium difluoride $G=T_{i} F_{2}[p, q, r]$, we have

$$
A(G)=\frac{131072}{125} p q r-\frac{745472}{3375}(p q+p r+q r)+\frac{76736}{3375}(p+q+r)+\frac{67264}{3375} \text {. }
$$

\section{Concluding Remarks and Discussion}

The M-polynomial is interesting, because it helps to compute the first and second Zagreb indices, the modified second Zagreb index, the Randić and Inverse Randić index, the Symmetric division index, the Inverse sum index, the Harmonic index, and the Augmented Zagreb index. Topological indices help us to predict many properties of the understudy molecular compound, for instance the Randić index is a topological descriptor that has been associated with various chemical properties of molecules and has been found to run parallel to preparing the boiling point and Kovats constants of the molecule. The first and second Zagreb indices were found to be useful for finding the total $\pi$-electron energy of the molecule. These are among the graph invariants, which were proposed for the estimation of the skeleton of the spreading of the carbon-molecule. Calculation of the distance based topological index of the understudy molecular graphs continues to be a fascinating open problem.

Author Contributions: W.G. designed the problem. A.F. and M.Y. proved the results. A.M. plot the results. W.N. wrote the paper and verify the results.

Funding: This work was supported in part by the National Natural Science Foundation of China (11761083).

Acknowledgments: Authors are thankful to the reviewers for positive suggestions that improve the quality of the research. We also thankful to Angela Toribio for his/her assistance.

Conflicts of Interest: The authors declare no conflict of interest.

\section{References}

1. Loghman, A.; Badakhshiana, L. PI polynomial of zig—zag polyhex nanotubes. Dig. J. Nanomater. Biostruct. 2008, 3, 299-302.

2. Baca, M.; Horvathova, J.; Mokrisova, M.; Semanicova-Fenovckova, A.; Suhanyiova, A. On topological indices of carbon nanotube network. Can. J. Chem. 2015, 93, 1157-1160. [CrossRef]

3. Gao, W.; Wang, W.; Dimitrov, D.; Wang, Y. Nano properties analysis via fourth multiplicative ABC indicator calculating. Arab. J. Chem. 2018, 11, 793-801. [CrossRef]

4. Gao, W.; Guirao, J.L.G.; Basavanagoud, B.; Wu, J. Partial multi-dividing ontology learning algorithm. Inform. Sci. 2018, 467, 35-58. [CrossRef]

5. Gao, W.; Iqbal, Z.; Ishaq, M.; Sarfraz, R.; Aamir, M.; Aslam, A. On eccentricity-based topological indices study of a class of porphyrin-cored dendrimers. Biomolecules 2018, 8, 71. [CrossRef] [PubMed]

6. Gao, W.; Wang, W.F. The fifth geometric-arithmetic index of bridge graph and carbon nanocones. J. Differ. Appl. 2016, 23, 100-109. [CrossRef]

7. Ahmad, M.S.; Nazeer, W.; Kang, S.M.; Imran, M.; Gao, W. Calculating degree-based topological indices of dominating david derived networks. Open Phys. 2017, 15, 1015-1021. [CrossRef]

8. Kang, S.M.; Zahid, M.A.; Virk, A.R.; Nazeer, W.; Gao, W. Calculating the degree-based topological indices of dendrimers. Open Chem. 2018, 16, 681-688. [CrossRef]

9. Gayathri, P.; Priyanka, U. Degree based topological indices of zig-zag chain. J. Math. Inform. 2017, 11, 83-93. [CrossRef]

10. Zhou, B.; Gutman, I. Relations between Wiener, hyper-Wiener and Zagreb indices. Chem. Phys. Lett. 2004, 394, 93-95. [CrossRef] 
11. Rucker, G.; Rucker, C. On topological indices, boiling points, and cycloalkanes. J. Chem. Inf. Comput. Sci. 1999, 39, 788-802. [CrossRef]

12. Klavžar, S.; Gutman, I. A comparison of the Schultz molecular topological index with the Wiener index. J. Chem. Inf. Comput. Sci. 1996, 36, 1001-1003. [CrossRef]

13. Brückler, F.M.; Došlić, T.; Graovac, A.; Gutman, I. On a class of distance-based molecular structure descriptors. Chem. Phys. Lett. 2011, 503, 336-338. [CrossRef]

14. Deng, H.; Yang, J.; Xia, F. A general modeling of some vertex-degree based topological indices in benzenoid systems and phenylenes. Comp. Math. Appl. 2011, 61, 3017-3023. [CrossRef]

15. Zhang, H.; Zhang, F. The Clar covering polynomial of hexagonal systems I. Discret. Appl. Math. 1996, 69, 147-167. [CrossRef]

16. Gutman, I. Some properties of the Wiener polynomials. Graph Theory Notes N. Y. 1993, 125, 13-18.

17. Deutsch, E.; Klavžar, S. M-Polynomial and degree-based topological indices. Iran. J. Math. Chem. 2015, 6, 93-102.

18. Munir, M.; Nazeer, W.; Rafique, S.; Kang, S.M. M-polynomial and related topological indices of nanostar dendrimers. Symmetry 2016, 8, 97. [CrossRef]

19. Munir, M.; Nazeer, W.; Rafique, S.; Nizami, A.R.; Kang, S.M. M-polynomial and degree-based topological indices of Titania nanotubes. Symmetry 2016, 8, 117. [CrossRef]

20. Kwun, Y.; Munir, M.; Nazeer, W.; Rafique, S.; Kang, S.M. M-polynomial and degree-based topological indices of V-phenalinic nanotubes and nanotori. Sci. Rep. 2017, 7, 8756. [CrossRef] [PubMed]

21. Munir, M.; Nazeer, W.; Rafique, S.; Nizami, A.R.; Kang, S.M. Some computational aspects of triangular boron nanotubes. Symmetry 2016, 9, 6. [CrossRef]

22. Munir, M.; Nazeer, W.; Rafique, S.; Kang, S.M. M-Polynomial and degree-based topological indices of polyhex nanotubes. Symmetry 2016, 8, 149. [CrossRef]

23. Gao, W.; Wu, H.; Siddiqui, M.K.; Baig, A.Q. Study of biological networks using graph theory. Saudi Bio. J. 2018, 25, 1212-1219. [CrossRef] [PubMed]

24. Gao, W.; Siddiqui, M.K.; Imran, M.; Jamil, M.K.; Farahani, M.R. Forgotten topological index of chemical structure in drugs. Saudi Pharm. J. 2016, 24, 258-264. [CrossRef] [PubMed]

25. Gao, W.; Wang, W. Second atom-bond connectivity index of special chemical molecular structures. J. Chem. 2014. [CrossRef]

26. Gao, W.; Wang, W.; Farahani, M.R. Topological indices study of molecular structure in anticancer drugs. J. Chem. 2016. [CrossRef]

27. Gao, W.; Wang, Y.; Basavanagoud, B.; Jamil, M.K. Characteristics studies of molecular structures in drugs. Saudi Pharm. J. 2017, 25, 580-586. [CrossRef] [PubMed]

28. Wiener, H. Structural determination of paraffin boiling points. J. Am. Chem. Soc. 1947, 69, 17-20. [CrossRef] [PubMed]

29. Dobrynin, A.A.; Gutman, I. Wiener index of trees: Theory and applications. Acta Appl. Math. 2001, 66, 211-249. [CrossRef]

30. Gutman, I.; Polansky, O.E. Mathematical Concepts in Organic Chemistry; Springer: New York, NY, USA, 1986.

31. Randić, M. On characterization of molecular branching. J. Am. Chem. Soc. 1975, 97, 6609-6615. [CrossRef]

32. Bollobás, B.; Erdös, P. Graphs of extremal weights. Ars Comb. 1998, 50, 225-233. [CrossRef]

33. Amić, D.; Bešlo, D.; Lučić, B.; Nikolić, S.; Trinajstić, N. The vertex-connectivity index revisited. J. Chem. Inf. Comput. Sci. 1998, 38, 819-822. [CrossRef]

34. Hu, Y.; Li, X.; Shi, Y.; Xu, T.; Gutman, I. On molecular graphs with smallest and greatest zeroth-Corder general Randić index. MATCH Commun. Math. Comput. Chem. 2005, 54, 425-434.

35. Caporossi, G.; Gutman, I.; Hansen, P.; Pavlovic, L. Graphs with maximum connectivity index. Comput. Biol. Chem. 2003, 27, 85-90. [CrossRef]

36. Li, X.; Gutman, I. Mathematical Aspects of Randić-Type Molecular Structure Descriptors; Mathematical Chemistry Monographs, No. 1; University of Kragujevac: Kragujevac, Serbia, 2006.

37. Kier, L.B.; Hall, L.H. Molecular Connectivity in Chemistry and Drug Research; Academic Press: New York, NY, USA, 1976.

38. Kier, L.B.; Hall, L.H. Molecular Connectivity in Structure-Activity Analysis; Wiley: New York, NY, USA, 1986.

39. Dimitrov, D. On structural properties of trees with minimal atom-bond connectivity index IV: Solving a conjecture about the pendent paths of length three. Appl. Math. Comput. 2017, 313, 418-430. [CrossRef] 
40. Gutman, I.; Furtula, B. (Eds.) Recent Results in the Theory of Randić Index; University of Kragujevac: Kragujevac, Serbia, 2008.

41. Randić, M. On History of the Randić Index and Emerging Hostility toward Chemical Graph Theory. MATCH Commun. Math. Comput. Chem. 2008, 59, 5-124.

42. Randić, M. The connectivity index 25 years After. Mol. Graph. Model. 2001, 20, 19-35. [CrossRef]

43. Li, X.; Shi, Y. A survey on the Randić index. MATCH Commun. Math. Comput. Chem. 2008, 59, 127-156.

44. Dimitrov, D.; Milosavljević, D. Efficient computation of trees with minimal atom-bond connectivity index revisited. MATCH Commun. Math. Comput. Chem. 2018, 79, 431-450.

45. Nikolić, S.; Kovačević, G.; Miličević, A.; Trinajstić, N. The Zagreb indices 30 years after. Croat. Chem. Acta 2003, 76, 113-124.

46. Gutman, I.; Das, K.C. The first Zagreb indices 30 years after. MATCH Commun. Math. Comput. Chem. 2004, 50, 83-92.

47. Das, K.C.; Gutman, I. Some properties of the second Zagreb index. MATCH Commun. Math. Comput. Chem. 2004, 52, 103-112.

48. Trinajstić, N.; Nikolić, S.; Miličević, A. Gutman On Zagreb indices. Kem. Ind. 2010, 59, 577-589. (In Croatian)

49. Vukičević, D.; Graovac, A. Valence connectivities versus Randić, Zagreb and modified Zagreb index: A linear algorithm to check discriminative properties of indices in acyclic molecular graphs. Croat. Chem. Acta 2004, 77, 501-508.

50. Huang, Y.; Liu, B.; Gan, L. Augmented Zagreb index of connected graphs. MATCH Commun. Math. Comput. Chem. 2012, 67, 483-494.

51. Chen, K.; Sun, C.; Song, S.; Xue, D. Polymorphic crystallization of $\mathrm{Cu}_{2} \mathrm{O}$ compound. Cryst Eng Comm 2014, 16, 52-57. [CrossRef]

52. Yuhas, B.D.; Yang, P. Nanowire-Based All-Oxide Solar Cells. J. Am. Chem. Soc. 2009, 131, $3756-3761$. [CrossRef] [PubMed]

53. Zhang, J.; Liu, J.; Peng, Q.; Wang, X.; Li, Y. Nearly monodisperse $\mathrm{Cu}_{2} \mathrm{O}$ and $\mathrm{CuO}$ nanospheres: preparation and applications for sensitive gas sensors. Chem. Mater. 2006, 18, 867-871. [CrossRef]

54. Cotton, F.A.; Wilkinson, G.; Murillo, C.A.; Bochmann, M. Advanced Inorganic Chemistry; John Wiley and Sons: Hoboken, NJ, USA, 1999.

(c) 2018 by the authors. Licensee MDPI, Basel, Switzerland. This article is an open access article distributed under the terms and conditions of the Creative Commons Attribution (CC BY) license (http:/ / creativecommons.org/licenses/by/4.0/). 